\title{
Media Alat Bantu Promosi Fakultas Teknik Berbasis Android Menggunakan Teknologi Augmented Reality
}

\author{
Siti Nazilah ${ }^{1}$ Tita Setiawati ${ }^{2}$ \\ Program Studi Teknik Informatika \\ Universitas Suryakancana \\ Zilah.nazilah@gmail.com ${ }^{1,}$ Thitzmia23@gmail.com ${ }^{2}$
}

\begin{abstract}
Abstrak
Media alat bantu Promosi Fakultas Teknik Berbasis Android menggunakan Teknologi Augmented Reality dengan Metode Marker Based Tracking dan dengan Menggunakan Metodeperangkat lunak yaitu MDLC (Multimedia development life cycle) di Fakultas Teknik Universitas Suryakancana Cianjur, Media alat bantu ini merupakan Media Teknologi untuk membantu mempromosikan Fakultas Teknik Universitas Suryakancana dengan secara virtual menggunakan Augmented Reality. Augmented Reality (AR) adalah suatu lingkungan yang memasukkan objek virtual 3D ke dalam lingkungan nyata. AR mengizinkan penggunanya untuk berinteraksi secara realtime. Penelitian ini akan memasukkan teknologi AR kedalam marker Gedung Fakultas Teknik, sehingga marker ini menjadi lebih real dengan adanya objek 3D pada Gedung Fakultas Teknik. Aplikasi ini merupakan aplikasi yang berjalan pada platform mobile android, dimana aplikasi AR ini memerlukan marker yang nantinya akan diambil dari kamera smartphone sebagai sumber masukan, kemudian aplikasi ini akan melacak dan mendeteksi marker (penanda) dengan menggunakan sistem tracking, setelah marker terdeteksi, model Gedung 3D pada Gedung Fakultas Teknik akan muncul diatas marker seolah-olah model Gedung tersebut nyata.
\end{abstract}

Kata Kunci : Fakultas Teknik Universitas Suryakancana, MDLC, Augmented Reality, Marker.

\begin{abstract}
Supporting media for Android-based Engineering Faculty using Augmented Reality Technology with Marker Based Tracking Method and by using MDLC (Multimedia development life cycle) method at the Faculty of Engineering, Suryakancana University, Cianjur, this tool media is a Media Technology to help promote the Faculty of Engineering,. virtually using Augmented Reality. Augmented Reality (AR) is an environment that incorporates $3 D$ virtual objects into a real environment. AR allows users to interact in realtime. This research will incorporate AR technology into the marker of the Faculty of Engineering Building, so that this marker becomes more real with the presence of $3 D$ objects in the Suryakancana University Faculty of Engineering Building. This application is an application that runs on the Android mobile platform, where this AR application requires a marker that will later be taken from a smartphone camera as an input source, then this application will track and detect markers (markers) using the tracking system, after markers are detected, the Building model 3D in Suryakancana University Faculty of Engineering Building will appear above the marker as if the building model is real.
\end{abstract}

Keywords: Faculty of Engineering, University of Suryakancana, MDLC, Augmented Reality, Marker.

\section{PENDAHULUAN}

Pemanfaatan teknologi Augmented Reality pada saat ini sudah dapat dikatakan suatu kebutuhan dan mempengaruhi kemajuan di berbagai aspek kehidupan, hadirnya teknologi Augmented Reality yang perkembangannya berlangsung secara berkesinambungan pada dekade terakhir ini telah meningkatkan efektivitas dan efisiensi dari proses bisnis yang ada secara signifikan. Tidak terkecuali proses teknologi Augmented Reality tentang mempromosikan Fakultas Teknik dengan menggunakan metode marker based tracking.

Augmented Reality (AR) adalah suatu lingkungan yang memasukkan objek virtual 3D ke dalam lingkungan nyata. (Mantasia, M., \& Jaya, H.) AR mengizinkan penggunanya untuk berinteraksi secara realtime. Penelitian ini akan memasukkan teknologi AR kedalam marker Gedung Fakultas Teknik, sehingga marker ini menjadi lebih real dengan adanya objek 3D pada Gedung Fakultas Teknik. Aplikasi ini merupakan aplikasi yang berjalan pada platform mobile android, dimana aplikasi AR ini memerlukan marker yang nantinya akan diambil dari kamera smartphone sebagai sumber masukan, kemudian aplikasi ini akan melacak dan mendeteksi marker (penanda) dengan menggunakan sistem tracking, setelah marker terdeteksi, model Gedung 3D pada Gedung Fakultas Teknik Universitas Suryakancana akan muncul diatas marker seolah-olah model Gedung tersebut nyata. Dengan adanya aplikasi ini diharapkan akan terjadi 
peningkatan minat Siswa/Siswi untuk masuk ke Fakultas Teknik Universitas Suryakanacana dan juga untuk meningkatan Promosi Fakultas Teknik Uninversitas Suryakancana Cianjur dengan efektif, cepat, akurat, dan dapat diakses dengan mudah, Augmented Reality Fakultas Teknik ini yang nantinya akan menampilkan tampilan gedung Fakultas Teknik Seperti Fasilitas, Kelas dan Juga Gedung Fakultas Teknik dengan tampilan 3D sehingga pengguna dapat mudah melihat apa saja bentuk fasilitas yang ada di Fakultas Teknik, membantu meringankan para pengguna SMK/SMA/MA untuk mengakses dan melihat seluruh informasi untuk masuk dan bergabung menjadi Mahasiswa Fakultas Teknik Universitas Suryakancana Cianjur dimana saja dan kapan saja, tanpa perlu datang langsung ke Fakultas Teknik Universitas Suryakancana Cianjur.

Fakultas Teknik merupakan salah satu Fakultas yang ada di lingkungan Universitas Suryakancana Cianjur, terletak di Jalan Pasir Gede Raya Cianjur, yang didirikan berdasarkan Surat Keputusan Mendiknas RI No. 100/D/O/2001 tanggal 2 Agustus 2001, Fakultas Teknik Universitas Suryakancana Cianjur saat ini memiliki 3 (tiga) Program Studi yaitu Teknik Informatika, Teknik Industri, dan Teknik Sipil. Kehadiran Program Studi yang ada di Fakultas Teknik Universitas Suryakancana Cianjur, diharapkan dapat mempersiapkan kebutuhan tenaga-tenaga profesional di Kabupaten Cianjur dalam pengembangan dan pembangunan bidang Teknologi di tingkat regional maupun nasional.

Berdasarkan hal tersebut sudah seharusnya Fakultas Teknik Universitas Suryakancana Cianjur memanfaatkan teknologi Augmented Reality yang sudah ada saat ini, Adapun untuk mengatasi permasalahan yang ada di Fakultas Teknik Universitas Suryakancana Cianjur khususnya dibagian Promosi Fakultas. Diperlukan pengimplementasian yang menggunakan aplikasi sabagai media pembantu Promosi Fakultas Teknik, untuk meningkatkan tingkat pemahaman dan ketertarikan seseorang dalam mendapatkan suatu informasi Fakultas Teknik dengan cara mudah dan cara lebih menarik.

Berdasarkan latar belakang masalah yang telah diuraikan diatas, dapat diidentifikasikan permasalahan sebagai berikut :

a. Bagaimana merancang sebuah aplikasi Augmented Reality yang dapat menampilkan gambaran Gedung Fakultas Teknik, Kelas, danFasilitas secara 3D.

b. Bagaimana merancang sebuah sistem aplikasi Augmented Reality yang dapat membantu proses informasi 3 Program Studi, Beasiswa, Waktu Pendaftaran, dan Persyaratan Pendaftaran.

c. Bagaimana merancang sebuah sistem aplikasi Augmented Reality yang dapat memudahkan proses Promosi Fakultas Teknik dengan Unik dan Menarik.

Maksud penelitian ini adalah untuk membuat pemanfaatan Teknologi Augmented Reality sebagai Promosi Fakultas Teknik Universitas Suryakancana Cianjur.
Tujuan yang akan dicapai pada penelitian ini adalah :

a. Memudahkan media promosi Fakultas Teknik Universiras Suryakancana dengan menggunakan aplikasi Augmented Reality berbasis Andorid.

b. Memudahkan masyarakat umum khususnya SMK/SMA/MA untuk mengetahui informasiinformasi Fakultas Teknik.

c. Memudahkan masyarakat umum khususnya SMK/SMA/MA untuk mengetahui bentuk gedung dan fasilits Fakultas Teknik Secara 3 (tiga) dimensi.

\section{II.METODE}

\subsection{Media}

Pengertian media adalah suatu alat perantara atau pengantar yang berfungsi untuk menyalurkan pesan atau informasi dari suatu sumber kepada penerima pesan. Secara etimologi kata "media" berasal dari bahasa Latin, yaitu "medius" yang artinya "tengah, perantara atau pengantar". Istilah "media" pada umumnya merujuk pada sesuatu yang dijadikan sebagai wadah, alat, atau sarana untuk melakukan komunikasi. Media berasal dari bahasa Latin "medium" yang berarti "perantara" atau "pengantar" Lebih lanjut, media merupakan sarana penyalur pesan atau informasi Jurnal Komunikasi Pendidikan, belajar yang hendak disampaikan oleh sumber pesan kepada sasaran atau penerima pesan tersebut.Penggunaan media pengajaran dapat membantu pencapaian keberhasilan belajar (Tafonao, T.). Media adalah alat atau sarana yang digunakan untuk menyampaikan pesan dari komunikator kepada khalayak. Ada beberapa pakar psikologi memandang bahwa dalam komunikasi antarmanusia, maka media yang paling dominasi dalam berkomunikasi adalah pancaindera manusia seperti mata dan telinga. Pesan - pesan yang diterima selanjutnya oleh pancaindera selanjutnya diproses oleh pikiran manusia untuk mengontrol dan menentukan sikapnya terhadap sesuatu, sebelum dinyatakan dalam tindakan (Cangara, 2002).

Berdasarkan media yang akan dibuat di Fakultas Teknik dapat disimpulkan bahwa media adalah alat perantara yang berfungsi untuk menyampaikan suatu informasi mengenai fakultas teknik universitas suryakancana tentang visi misi, beasiswa, waktu pendaftaran, persyaratan pendaftaran, fasilitas serta gambaran gedung Fakultas Teknik dengan menggunakan media berbasis Android menggunakan teknologi Augmented Reality.

\subsection{Promosi}

Bagi produsen, promosi adalah kegiatan untuk menginformasikan produk atau jasa, membujuk konsumen untuk membeli serta mengingatkan para konsumen untuk tidak melupakan produk. Sementara bagi konsumen, pengertian promosi adalah komunikasi antara produsen dan konsumen. Kegiatan promosi adalah salah satu cara perusahaan (barang/jasa) untuk meningkatkan volume penjulan produknya.

Promosi ialah suatu upaya atau kegiatan perusahaan dalam mempengaruhi konsumen aktual maupun 
konsumen potensial agar mereka mau melakukan pembelian terhadap produk yang ditawarkan saat ini atau dimasa yang akan dating (Sistaningrum, 2002;98).

Promosi adalah segala macam bentuk komunikasi persuasi yang dirancang untuk menginformasikan pelanggan tentang produk atau jasa dan untuk memengaruhi mereka agar membeli barang atau jasa ersebut yang mencakup publisitas, penjualan perorangan dan periklanan (Zimmerer, 2002). Berdasarkan promosi yang akan dibuat di Fakultas Teknik dapat disimpulkan bahwa promosi adalah kegiatan untuk menginformasikan dengan bentuk komunikasi membuat suatu Augmented Reality menggunakan android untuk mempromosikan fakultas teknik itu sendiri, produk Augmented Reality ini dirancang untuk menginformasikan kepada siswa siswi yang ingin masuk perkuliahan fakultas teknik dan membujuk siswa siswi untuk masuk ke Fakultas Teknik Universitas Suryakancana.

\subsection{Augmented Reality}

Augmented Reality ( AR ) adalah sebuah istilah untuk lingkungan yang menggabungkan dunia nyata dan dunia virtual yang dibuat oleh komputer sehingga batas antara keduanya menjadi sangat tipis. Sistem ini lebih dekat kepada lingkungan nyata "real", karena itu, reality lebih diutamakan pada sistem ini (Brian, 2012). Augmented Reality adalah teknologi yang menggabungkan benda maya dua dimensi dan ataupun tiga dimensi ke dalam sebuah lingkungan nyata tiga dimensi lalu memproyeksikan benda-benda maya tersebut dalam waktunyata.Tidak seperti realitas maya yang sepenuhnya menggantikan kenyataan, namun Augmented Reality hanya menambahkan atau melengkapi kenyataan. Benda-benda maya menampilkan informasi yang tidak dapat diterima oleh pengguna dengan inderanya sendiri.Hal ini membuat Augmented Reality sesuai sebagai alat untuk membantu persepsi dan interaksi penggunanya dengan dunia nyata.Informasi yang ditampilkan oleh benda maya membantu pengguna melaksanakan kegiatan - kegiatan dalam dunia nyata.

\subsection{Metode Based Tracking}

Marker Augmented Reality (Marker Based

Tracking) Marker biasanya merupakan ilustrasi hitam dan putih persegi dengan batas hitam tebal dan latar belakang putih. Komputer akan mengenali posisi dan orientasi marker dan menciptakan dunia virtual $3 D$ yaitu titik $(0,0,0)$ dan tiga sumbu yaitu $\mathrm{X}, \mathrm{Y}$, dan Z. Marker Based Tracking ini sudah lama dikembangkan sejak 1980-an dan pada awal 1990-an mulai dikembangkan untuk penggunaan Augmented Reality. untuk penggunaan Augmented Reality.

\subsection{Metode Penelitian dan Metode Pengembangan \\ Perngkat Lunak}

Metode penelitian yang digunakan adalah deskriptif, yaitu suatu metode dengan cara mengumpulkan data, mengolah, serta menganalisa data yang telah terkumpul kemudian ditarik kesimpulan dan diberkan saran-saran yang diperlukan.

Metode perankat lunak yang digunakan adalah $M D L C$ (Multimedia Development Life Circle)-masing.

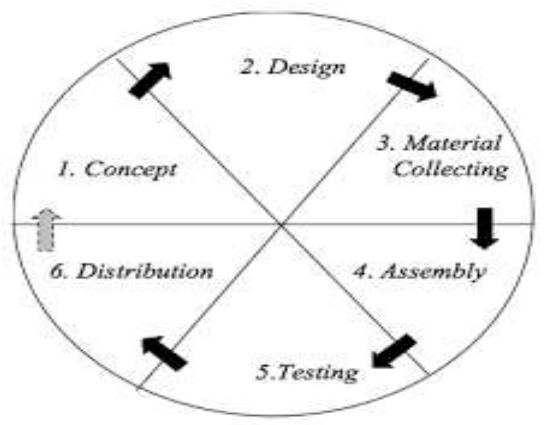

Gambar 1. Model MDLC

\section{III.PEMBAHASAN}

\subsection{Concept}

Tahap concept (konsep) adalah tahapan untuk menentukan tujuan dan siapa pengguna program (identifikasi audience). Rincian konsep pada penelitian ini terdapat pada tabel berikut :

\begin{tabular}{|c|c|}
\hline Kategori Konsep & Deskripsi Konsep \\
\hline Judul & $\begin{array}{l}\text { Media Alat Bantu Promosi } \\
\text { Fakultas Teknik Berbasis } \\
\text { Android Menggunakan } \\
\text { Teknologi Augmented } \\
\text { Reality Dengan Metode } \\
\text { Marker Based Tracking }\end{array}$ \\
\hline Jenis Multimedia & $\begin{array}{lr}\text { Media Gedung } & \text { Fakultas } \\
\text { Teknik } & \text { Universitas } \\
\text { Suryakancana } & \text { berbasis } \\
\text { Augmented Reality } & \\
\end{array}$ \\
\hline Tujuan & $\begin{array}{l}\text { Membuat } \\
\text { mengimplementasikan } \\
\text { aplikasi berbasis } \\
\text { Augmented Reality } \\
\text { sebagai media Promosi } \\
\text { Fakultas Teknik Universitas } \\
\text { Suryakancana. Agar dapat } \\
\text { membantu } \\
\text { mempermudah dan } \\
\text { pengguna untuk melihat } \\
\text { bagian Gedung yang ada } \\
\text { di Fakultas Teknik } \\
\text { Universitas Suryakancana. }\end{array}$ \\
\hline Sasaran & $\begin{array}{lr}\text { Masyarakat } & \text { umum dan } \\
\text { Siswa-Siswi } & \text { sekolah } \\
\text { SMK/SMA } & \text { MA/MAN } \\
\text { Sederajat. } & \\
\end{array}$ \\
\hline Audio & $\begin{array}{l}\text { Backsound ashamaluev } \\
\text { cooking dan Suara Nama } \\
\text { Ruangan Fakultas Teknik } \\
\text { Universitas Suryakancana. }\end{array}$ \\
\hline Gambar & Menggunakan gambar 3D \\
\hline Text & Nama Ruangan \\
\hline
\end{tabular}


1. Flowchart Menu Utama

Berikut adalah penjelasan Flowchart dari menu utama.

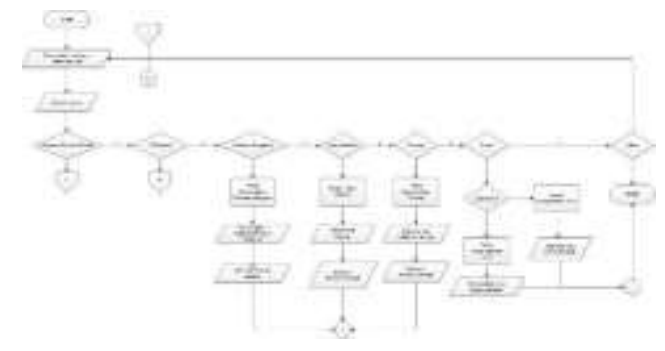

Gambar 1. Flowchart Menu Utama

2. Flowchart Informasi Fakultas Teknik

Berikut adalah penjelasan Flowchart dari menu AR Informasi Fakultas Teknik.

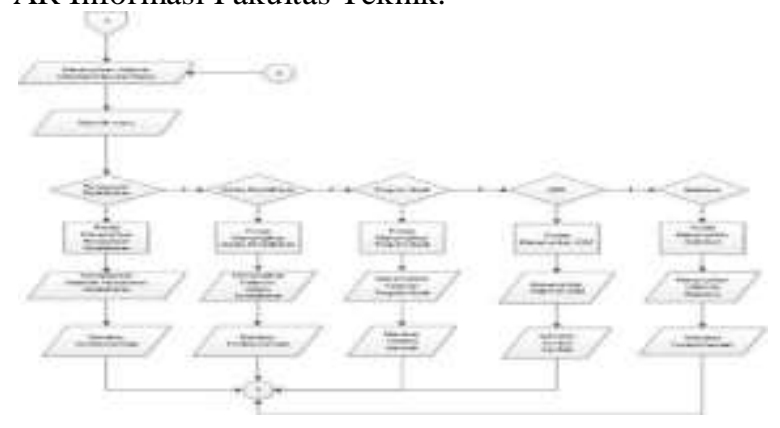

Gambar 2. Flowchart Informasi Fakultas Teknik

3. Flowchart AR Kamera

Kamera

Berikut adalah penjelasan Flowchart AR

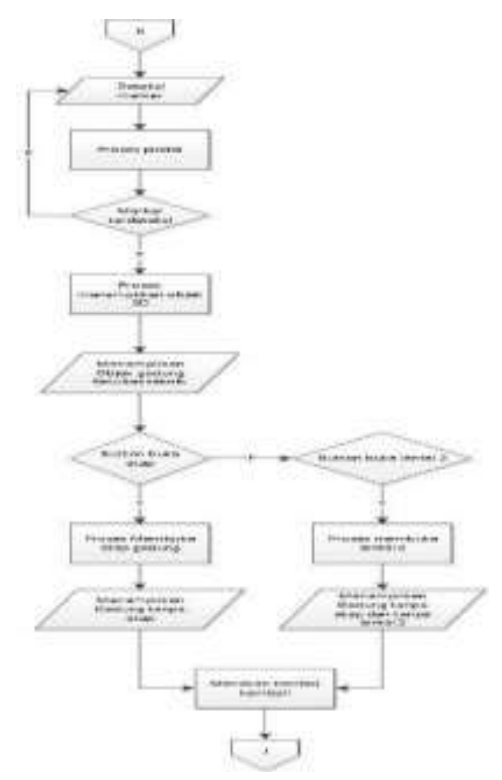

Gambar 3. Flowchart AR Kamera

4. State Transition Diagram Menu Utama
Berikut adalah penjelasan dari STD Menu Utama

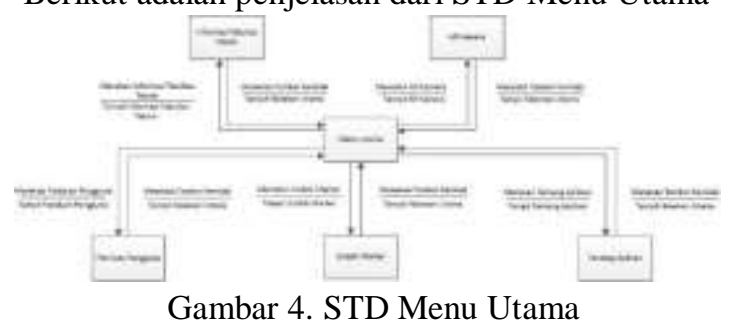

5. State Transition Diagram Informasi Fakultas Teknik

Berikut adalah penjelasan dari STD Informasi

Fakultas Teknik

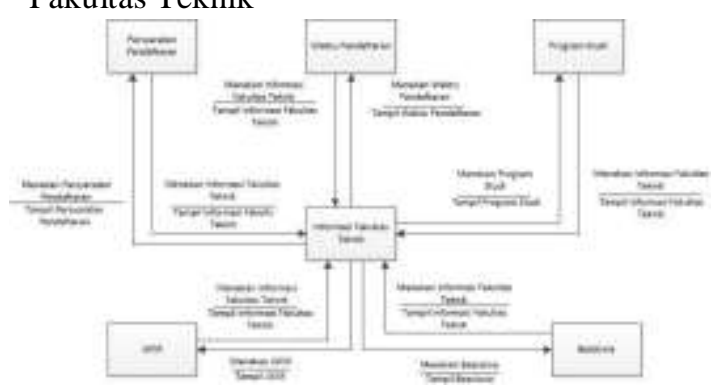

Gambar 5. STD Pindai Marker

6. State Transition Diagram AR Kamera Berikut adalah penjelasan dari STD AR Kamera

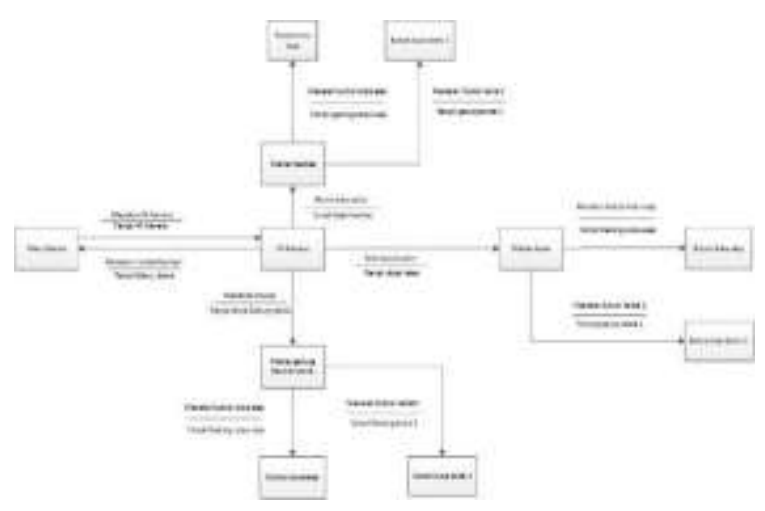

Gambar 6. STD AR Kamera

7 Struktur Navigasi

Berikut Adalah Struktur Navigasi AR Media Alat Bantu Promosi Fakultas Teknik

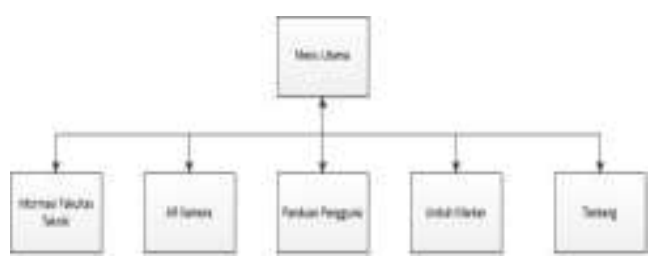

Gambar 7. Struktur Menu

IV. HASIL PENELITIAN

Perancangan antarmuka dilakukan untuk mempermudah dalam implementasi sistem yang akan dibangun. Tujuan dari perancangan antarmuka adalah memberi gambaran mengenai antarmuka pengguna yang digunakan pada sistem yang akan dibuat dan 
memperjelas alur program dari segi tampilan.

1. Antarmuka Menu Utama

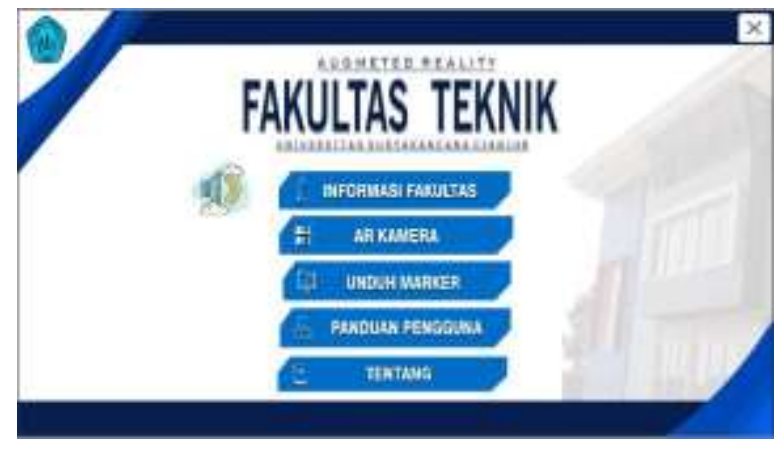

Gambar 1. Antarmuka Menu Utama

Gambar diatas merupakan tampilan menu utama dari aplikasi AR Media Alat Bantu Promosi Fakultas Teknik yang didalamnya terdapat beberapa menu.

2. Antarmuka Informasi Fakultas Teknik

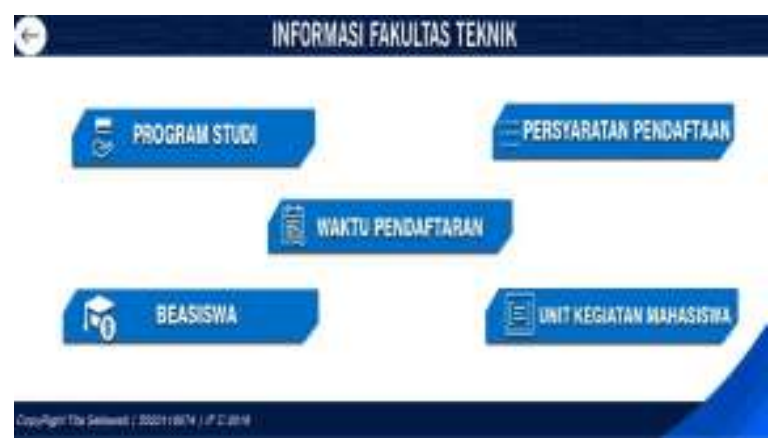

Gambar 2. Antarmuka Informasi Fakultas Teknik

Gambar diatas merupakan tampilan pada saat pengguna menekan tombol Informasi Fakultas Teknik pada menu utama, dan diarahkan pada tampilan halaman Informasi Fakultas Teknik.

3. Antarmuka Program Studi

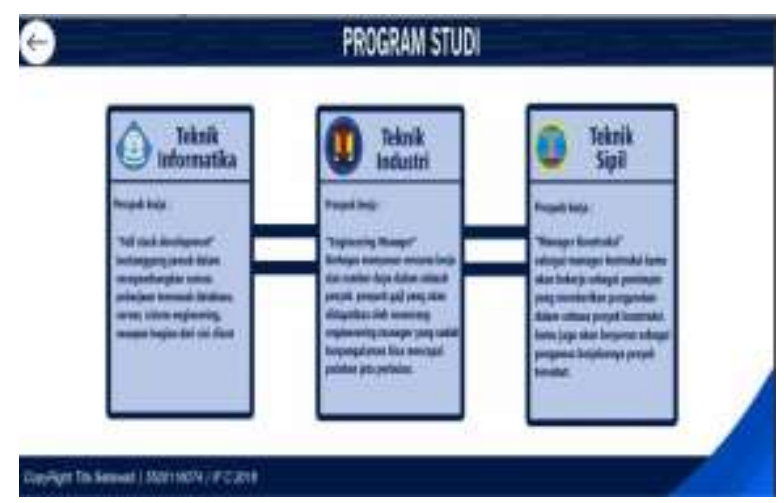

Gambar 3. Antarmuka program Studi

Gambar diatas merupakan tampilan pada saat pengguna menekan tombol Program studi, dan akan diarahkan pada halaman Program Studi.

4. Antarmuka Waktu Pendaftaran

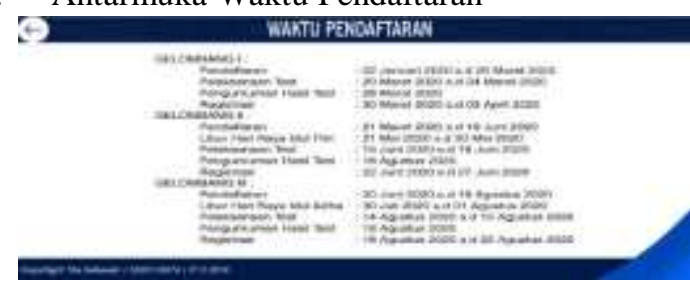

Gambar 4. Antarmuka Waktu Pendaftaran

Gambar diatas merupakan tampilan pada saat pengguna menekan tombol waktu pendaftaran pada menu informasi fakultas teknik, dan diarahkan pada tampilan halaman waktu pendaftaran

5. Antarmuka Persyaratan Pendaftaran

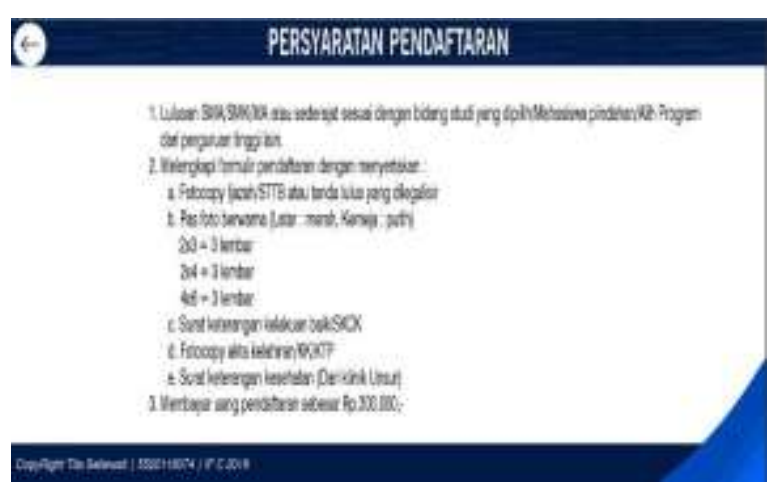

Gambar 5. Antarmuka Persyaratan Pendaftaran

Gambar diatas merupakan tampilan pada saat pengguna menekan tombol Persyaratan Pendaftaran pada menu informasi fakultas teknik, dan diarahkan pada tampilan halaman Persyaratan Pendaftaran.

6. Antarmuka Beasiswa

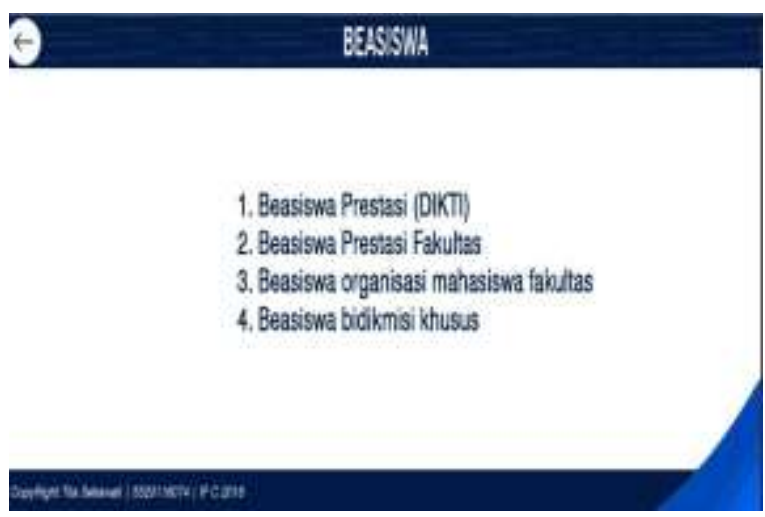

Gambar 6. Antarmuka Beasiswa

Gambar diatas merupakan tampilan pada saat pengguna menekan tombol Beasiswa pada menu informasi fakultas teknik, dan diarahkan pada tampilan halaman Beasiswa. 
Panduan Pengguna.

10. Antarmuka Tentang Aplikasi

7. Antarmuka Unit Kegiatan Mahasiswa

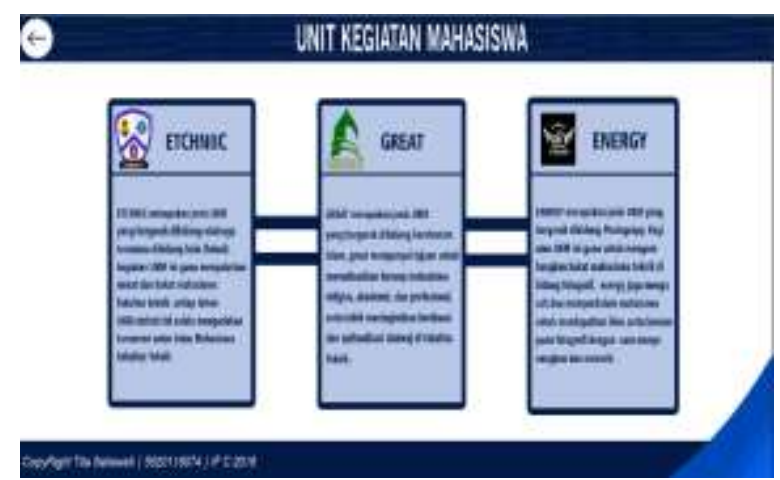

Gambar 7. Unit Kegiatan Mahasiswa

Gambar diatas merupakan tampilan pada saat pengguna menekan tombol Unit Kegiatan Mahasiswa pada menu Informasi Fakultas Teknik, dan diarahkan pada tampilan halaman Unit Kegiatan Mahasiswa.

8. Antarmuka Unduh Marker

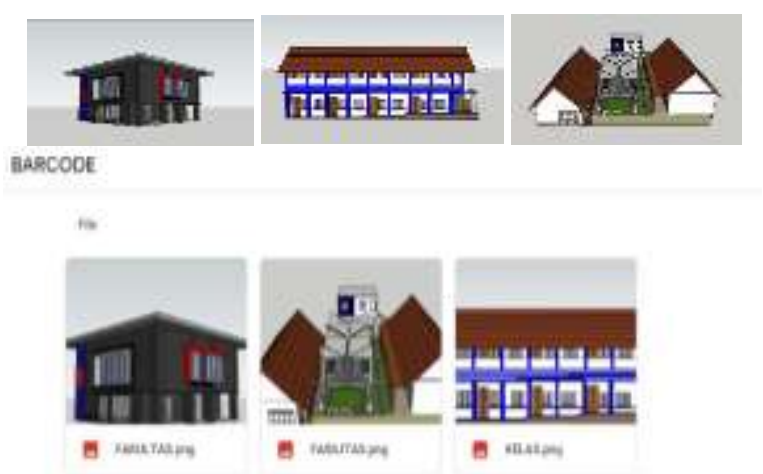

Gambar 8. Unduh Marker

Gambar diatas merupakan tampilan pada saat pengguna menekan tombol Unduh Marker pada menu utama, dan diarahkan pada tampilan halaman Unduh Marker.

9. Antarmuka Panduan Pengguna

\section{$\theta$}

\section{PANDIAN PERIGGLYA}

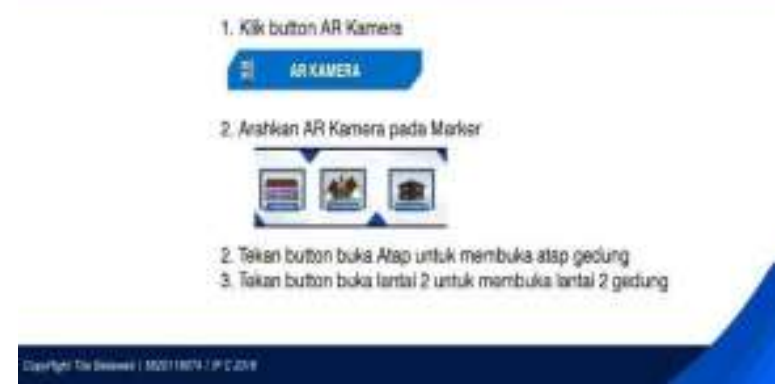

Gambar 9. Panduan Pengguna

Gambar diatas merupakan tampilan pada saat pengguna menekan tombol Panduan Pengguna pada menu utama, dan diarahkan pada tampilan halaman

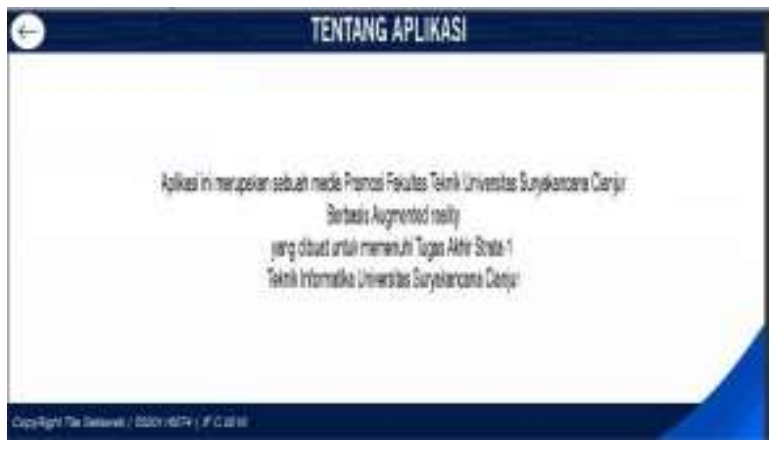

Gambar10. Tentang Aplikasi

Gambar diatas merupakan tampilan pada saat pengguna menekan tombol Tentang Aplikasi pada menu utama, dan diarahkan pada tampilan halaman Tentang Aplikasi.

\section{KESIMPULAN}

Berdasarkan hasil analisis, perancangan dan implementasi selama melaksanakan penelitian Tugas Akhir yang berjudul Media Alat Bantu Promosi Fakultas Teknik Berbasis Android Menggunakan Teknologi Augmented Reality Dengan Metode Marker Based Tracking dapat disimpulkan bahwa :

1. Telah dibangun Media Alat Bantu Promosi

Fakultas Teknik Berbasis Android Menggunakan

Teknologi Augmented Reality yang dapat memudahkan media promosi Fakultas Teknik Universiras Suryakancana dengan menggunakan aplikasi Augmented Reality berbasis Andorid.

2. Telah dibangun Media Alat Bantu Promosi Fakultas Teknik Berbasis Android Menggunakan Teknologi Augmented Reality yang dapat memudahkan masyarakat umum khususnya SMK/SMA/MA untuk mengetahui informasiinformasi Fakultas Teknik.

3. Telah dibangun Media Alat Bantu Promosi Fakultas Teknik Berbasis Android Menggunakan Teknologi Augmented Reality yang dapat memudahkan masyarakat umum khususnya SMK/SMA/MA untuk mengetahui bentuk gedung dan fasilits Fakultas Teknik Secara 3 (tiga) dimensi.

Untuk meningkatkan kinerja aplikasi augmented reality sebagai media Promosi Fakultas Teknik Unsur, disarankan untuk :

1. Mengganti Judul Penelitian Tugas Akhir ini. Karena dengan judul Media Alat Bantu Promosi Fakultas Teknik Berbasis Android Menggunakan Teknologi Augmented Reality Dengan Metode Marker Based Tracking dengan isi konteks yang ada itu kurang relevan dan efektif.

2. diharapkan kedepannya aplikasi ini dikembangan dengan berbagai informasi, penambahan video, dan memanfaatkan teknologi augmented reality dengan fitur yang lebih menarik 
dan penampilan objek yang lebih jelas sehingga pengguna masyarakat Khususnya SMA/MA/MAN dapat melihat bangunan- bangunan gedung yang ada di Fakultas Teknik Universitas Suryakancana dengan secara terperinci.

\section{VI.REFERENSI}

[1]. Barakbah, A. R. 2013. Logika Dan Algoritma. Surabaya: Departemen Teknik formatika dan Komputer Politeknik Elektronika Negeri Surabaya.

[2]. Ellinda Dwi Fransiska, dkk. 2017. Implementasi Teknologi Augmented Reality Sebagai Media Pembelajaran Informatif Dan Interaktif Untuk Pengenalan Hewan. Seminar Nasional Sistem Informasi Fakultas Teknologi Informasi UNMER Malang, 637-638.

[3]. Mahnun.Nunu.(2012). Media Pembelajaran (Kajian terhadap Langkah-langkah Pemilihan Media dan Implementasinya dalam Pembelajaran). Dalam Jurnal Pemikiran Islam; Vol. 37, No. 1: 27.

[4]. Mantasia, M., \& Jaya, H. (2016). Pengembangan Teknologi Augmented Reality Sebagai Penguatan Dan Penunjang Metode Pembelajaran Di Smk Untuk Implementasi Kurikulum 2013. Jurnal Pendidikan Vokasi, 6(3), 281. https://doi.org/10.21831/jpv.v5i3.10522

[5]. Mumtahana, H. A. (2017). Perancangan Teknologi Augmented Reality Pada Brosur Stt Dharma Iswara Madiun. DOUBLECLICK: Journal of Computer and Information Technology, 1(1), 6. https://doi.org/10.25273/doubleclick.v1i1.1320

[6]. Mustaqbal, d. (2015). Pengujian Aplikasi Menggunakan Black Box Testing . Nasution, Y. R. (2018). Penerapan Aplikasi Online Angket Persepsi Mahasiswa

[7]. Terhadap Kinerja Dosen Uin Sumatera Utara Medan. JISTech, 3(2), 20-35. https://doi.org/10.30829/jistech.v3i2.3158

[8]. Nugroho. 2009. Pengertian Unified Modeling Language ( UML ) dan Modelnya Menurut Pakar dan Ahli. Retrieved agustus 15, 2019.

[9]. Rizky, s. 2011. Konsep Dasar Rekayasa Perangkat Lunak. Jakarta: Prestasi Pustaka. Shalahuddin., R. R. 2015. Rekayasa Perangkat Lunak Terstruktur Dan Berorientasi Objek. Bandung : Informatika. 